\title{
Development of Modular Robotic Design Concepts for Hot Cell Applications
}

\author{
Ahmed Sherif El-Gizawy ${ }^{1,2 *}$, Abdulraheem Kinsara ${ }^{2}$, Ghassan Mousa ${ }^{2}$ and Andrew Gunn ${ }^{1}$ \\ ${ }^{1}$ Industrial and Technological Development Center Mechanical and Aerospace Engineering, University of Missouri-ColumbiaColumbia, Missouri-65211, USA \\ ${ }^{2}$ Center of Excellence for Industrial Design and Manufacturing Research (CEIDM) Faculty of Engineering, King Abdulaziz University Jeddah, Saudi Arabia
}

\begin{abstract}
The production of isotopes for diagnosis and treatment of cancer patients involves handling and processing of irradiated materials. This process is performed inside heavily shielded workstations termed Hot Cells. A modular robotic design for handling irradiated materials inside hot cells is introduced. The new robotic system is reconfigurable in order to enhance versatility of applications and precision of its tasks. The reliability of the introduced robot control system is assessed using Failure Trees (FT) Methodology. The technology developed in the present work allows for improving productivity and cost effectiveness for production of medical isotopes.
\end{abstract}

Keywords: Modular robotic design; Kinematics and control strategy; Hot cell; Medical isotopes

\section{Introduction}

The production of medical isotopes, involves handling and processing of irradiated materials. It is performed inside heavily shielded workstations termed Hot Cells. Most of the handling tasks inside hot cells are conducted with the aid of master-slave mechanical manipulators in order to reduce radiation exposure to operators. Figure 1 displays a pair of such manipulators that are currently used in the production of isotopes inside hot cells. These manipulators transfer the kinematic motion of user-operated controls located outside the hot cell, to end effector claws inside the hot cell [1]. Nevertheless, they are bulky structures, slow in motion and suffer from not capable of transferring rotational motion with precision, and very expensive (exceeding $\$ 200,000$ per unit). An effective alternative for handling radioactive materials inside hot cells is the use of cost effective semiautonomous robots $[1,2]$. The main objective of the present research is to develop and support modular robotic design concepts to improve task versatility, reduce personnel radiation exposure, and improve productivity and cost effectiveness in production of radioactive isotopes.

The design requirements for the required robots should follow the reported conditions [1-5]. The platform should cope with different types of applications inside the hot cell to ensure mobility and accuracy in positioning. The platform has to have rigid structure to be able to carry sensor and tools payload without excessive deformation. These requirements, in addition to the nature of the radioactive environment, impose important constraints on the motor power and the power supply.
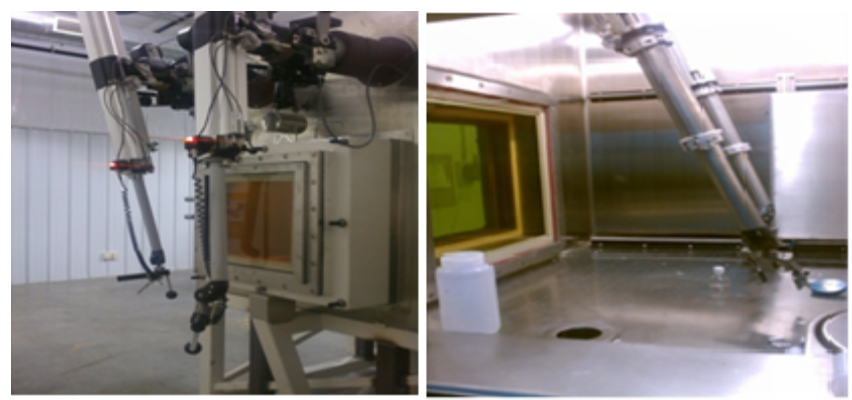

Figure 1: Operators control manipulators that mimic the human movement through pneumatic servos and hydraulics, used for handling tasks inside hot cells.
Hence, all evolved design specifications should ensure reliable deployability of the introduced modular robots for hot cell environment.

\section{The engineering design process}

The design process road map [2] is used in the present work for developing the required devices. It illustrates the flow of the design process from preconception, to conceptualization, to configuration, and lastly, to design finalization and validation.

\section{Quality function deployment}

The Quality Function Deployment (QFD) is a preliminary planning mechanism that is used to aid in the design process. The QFD relates the customer needs to specific engineering characteristics of the potential design to better understand which characteristics have greater priority over others. The Quality Function Deployment for the Single-Arm Robot can be seen in Figure 2. Three classes of requirements are included in the reported QFD: Functions; Ergonomics; and Constraints (cost, size, environment). The most important engineering characteristics are shown to be: remote robust control of motion, high degree of freedom, and the ability to perform in a high risk environment (radioactive tolerance).

\section{Kinematics and control strategy}

Kinematics analysis is applied to the design concepts of modular robots. It refers to the determination of required joint values and end effector values, as done in path planning. The kinematic equations of the manipulator can be used to handle redundancies (different combinations of joint angles that produce the same end effector orientation and position), collision avoidance, and avoidance of singularity solutions [3]. Once the kinematic equations have been

${ }^{*}$ Corresponding author: El-Gizawy AS, University of Missouri-Columbia, USA Tel: 5738826641; Fax: 5738845090; E-mail: sherifelg@yahoo.com

Received July 22, 2016; Accepted September 20, 2016; Published September 23, 2016

Citation: El-Gizawy AS, Kinsara A, Mousa G, Gunn A (2016) Development of Modular Robotic Design Concepts for Hot Cell Applications. Adv Robot Autom 5: 154. doi: 10.4172/2168-9695.1000154

Copyright: (c) 2016 El-Gizawy AS, et al. This is an open-access article distributed under the terms of the Creative Commons Attribution License, which permits unrestricted use, distribution, and reproduction in any medium, provided the original author and source are credited. 
developed, they can be used to create a dynamic model of the robot, whereupon the effects of forces upon movements are analyzed. The results of this analysis are used to improve the control algorithms of the robot. The control system and electronics for robots are analyzed for robustness. Evaluation of power sources (batteries... etc.) to be used is conducted for optimum battery configuration. The introduced control system for modular robots is wireless using Bluetooth wireless capabilities.

\section{Modular robot structural design requirements}

In order to reduce cost of materials and manufacturing of the required devices, thermoplastic with high strength are used in construction of most of the structure components. Most polymers and elastomers are not significantly affected by radiation doses below 10,000 Gy (1 Mrad). Teflon is a unique exception and parts that include Teflon insulation must be replaced by parts using less affected insulation. For example, hookup wire with cross-linked polyolefin insulation is tolerant to a radiation dose of $1 \mathrm{MGy}$. Structural analysis for strength and failure are conducted using the FEM Simulation of SOLIDWORKS computer aided design and engineering platform.

\section{Design for manufacturing and assembly}

Upon realizing the initial concepts of modular robot, all of them and their components are reviewed and modified for ease of assembly and manufacturing by Direct Digital Manufacturing (DDM) technique. DDM describes a class of relatively new manufacturing process in which parts are fabricated by additive manufacturing. In this process, parts are fabricated layer-by-layer in thin cross sections from geometries supplied by a computer aided (CAD) model of the part. One of the key benefits of this type of manufacturing is the ability to achieve complex and intricate geometries that could not be done with conventional methods (e.g. ducting with internal features). This, in combination with the fact that no expensive tools are required to produce a part dramatically, reduces lead times that would otherwise be required to produce functional products [6]. Additionally, DDM processes use much less material than conventional methods because fabrication is a result of adding material instead of removing it, thus reducing waste. At the time the present project was undergoing, the research teams have access to DDM technologies at both MU and KAU, specifically Fusion Deposition Modeling (FDM) and Selective Laser Sintering (SLS). FDM process is displayed in Figure 3, while SLS is displayed on Figure 4. Both technologies were use in the early prototypes. Because FDM uses larger variety of thermoplastic materials than SLS, the final concepts were built using FDM process.

DDM (3D Printing) by fused deposition modeling (FDM) is a manufacturing process that creates parts by depositing polymer filaments in successive layers (Figure 3). The polymer filament passes through the extrusion nozzle, which heats the filament to a semimolten state and deposits it on the build platform [6]. The platen build platform then descends within the work build chamber to allow for the deposition of the next layer upon the previous one. The variety of materials available, ease of producing complex geometries, and extremely fast fabrication times make FDM a very attractive manufacturing option for several industries.

\section{Modular robotic design and testing}

Following the engineering design process presented earlier, a modular robot was developed to be reconfigurable in order to perform

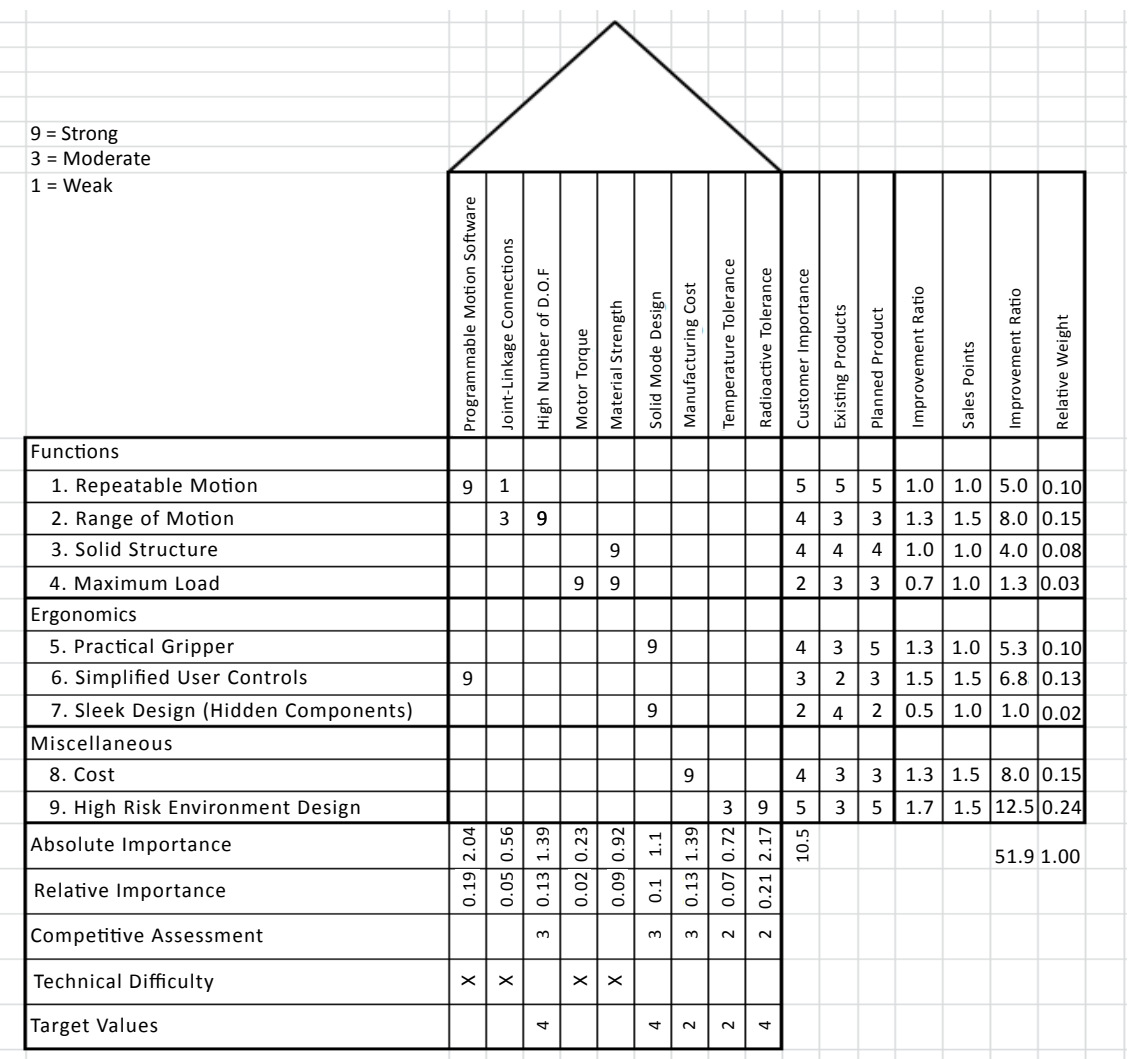

Figure 2: QFD for a modular robot. 


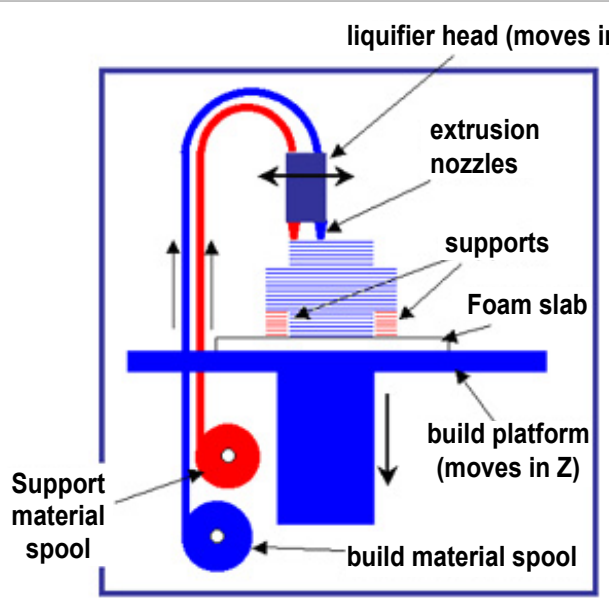

Figure 3: Fusion deposition modeling (FDM) technique for rapid digita manufacturing.

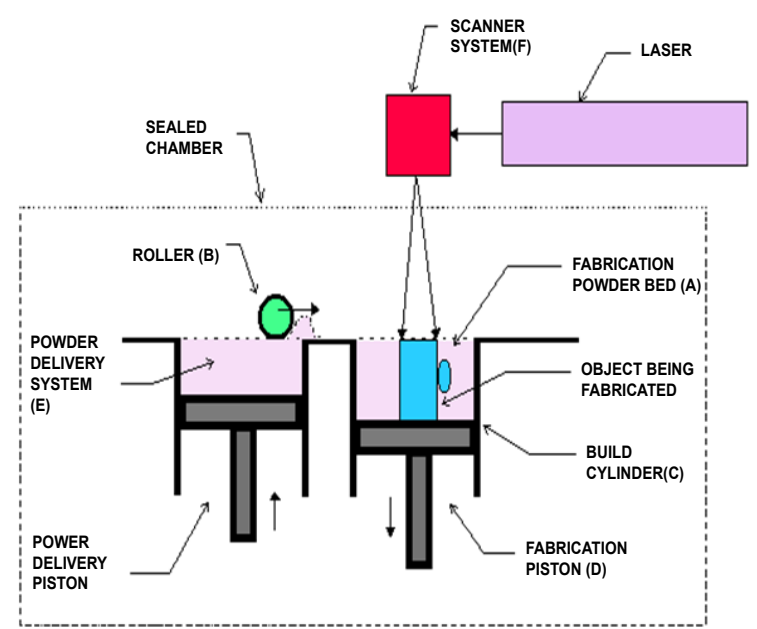

Figure 4: Selective laser sintering (SLS) technique for rapid digital manufacturing.

different materials handling and processing tasks inside hot cells. The first concept selected for evaluation is the two-arm robot moving on tracks (Figure 5).

The goal of the initial kinematic analysis was to determine the "envelope" of the Robot. At its resting position, the robot measures 5.95 in wide $\times 12.95$ in tall $\times 10.74$ in deep. The robot was animated to achieve its most extreme positions. The analysis indicates that the envelope of the first configuration of the Modular Robot is 19.62 in wide $\times 16.66$ in tall $\times 15.54$ in deep. When redesigning the robot chassis, the battery and control boards must be considered along with additional space for wiring. All of the electrical control components can be inserted and attached to the main chassis of the robot. A top view and cutaway top view of the robot chassis can be seen in Figures 6 and 7. The battery was the largest component and was given space underneath the center of the robot. The battery slides into place and is secured using an end cap that can be inserted into a slot on the front of the robot. In the back of the robot, the motor control board is inserted into a slot at the bottom of the chassis cavity. The voltage regulator and $9 \mathrm{~V}$ battery are inserted into side channels along the main battery slot. The servo board is then screwed down on the top of the cavity with the servo control board underneath. All of the wiring is fed to the motor control board through a slot in front of it. The servo board is also rotated so that the serial port is directly out of the back of the robot. This orientation will allow for connection of a serial cable to the port without interference with the tracks. The Bluetooth board is secured to the top of the chassis near the servo board via double sided tape. The torso turret was also repositioned to allow easier connection of motor wires to the track motors. Figure 8 displays the redesigned Electrical System for efficient assembly.
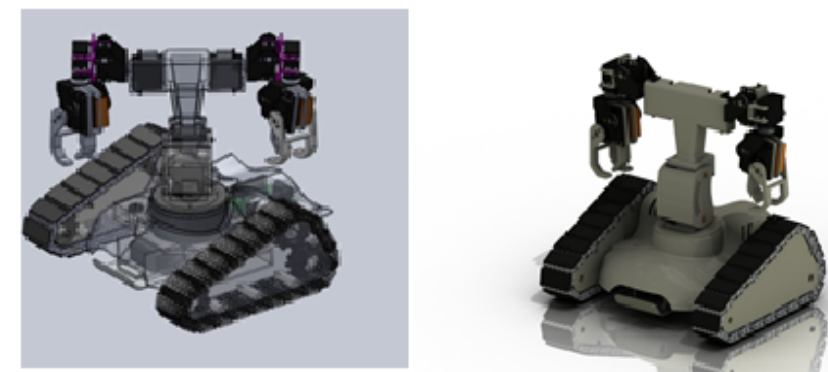

Figure 5: Two-arm modular robot on tracks

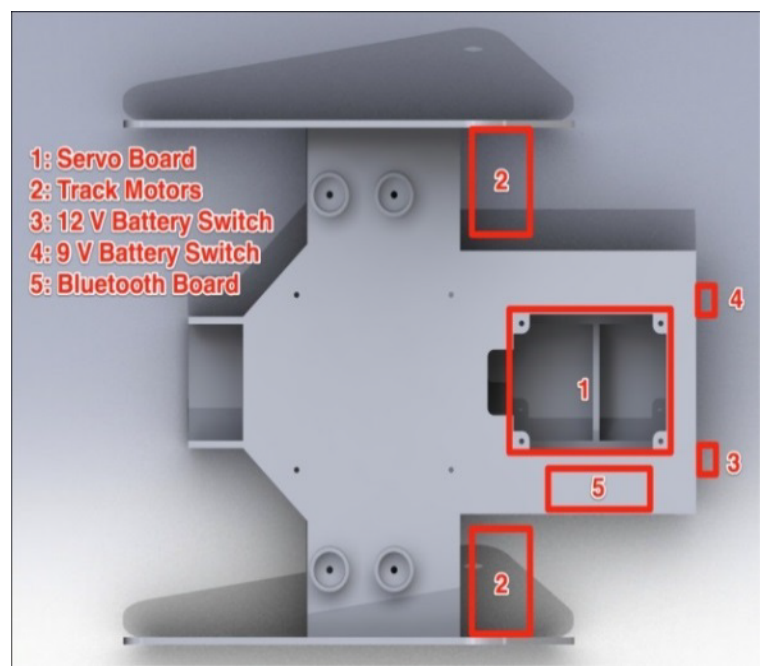

Figure 6: Top view of robot chassis

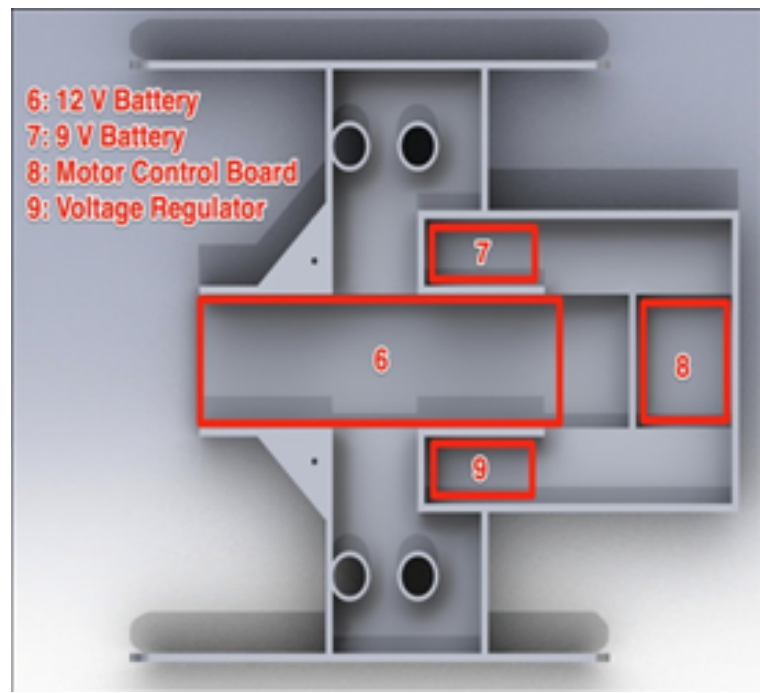

Figure 7: Cutaway top view. 
Citation: El-Gizawy AS, Kinsara A, Mousa G, Gunn A (2016) Development of Modular Robotic Design Concepts for Hot Cell Applications. Adv Robot Autom 5: 154. doi: 10.4172/2168-9695.1000154

Page 4 of 6

\section{Assembly of final prototype}

Figure 9 explain about Exploded view and Final Product of the Redesigned Robot for Efficient Assembly.

\section{Assessing reliability of the developed modular robot}

In order to assess the reliability and risk level of different systems in the new Modular Robot, fault tree analysis was conducted on all of them. A fault tree analysis for the electronics and control system of the robot is displayed in Figure 10. The top event of the tree is the failure of the electronic system. This event can occur if four other events happen, which include motor board failure, servo board failure, servo failure or motor failure. If failure occurs in the motor board, the tracks will not be able to move. If the servo board fails, then the servomotors will not be able to control the position of the torso and arms. The board failures can be caused by three different events, electrical shortages, power loss, Bluetooth out of range. The estimated failure rate of the robot control system during operation is $2 \%$, which is considered acceptable for the intended applications.

Experimental verification of the performance of a single arm of the developed modular robot was tested using the experimental setup displayed in Figure 11. Initial testing began with rudimentary motions controlled by computer Servo Position inputs. Basic functions allowed for co-ordinates to be input to the arm and the arm would move to the location. Several objects vary in size were used for evaluating the functions of the developed robotic system. Accuracy analysis in determining object position and orientation was performed using repeated tests. The attached vision system determines the orientation of an object and location in X-Y coordinates. The followings are samples

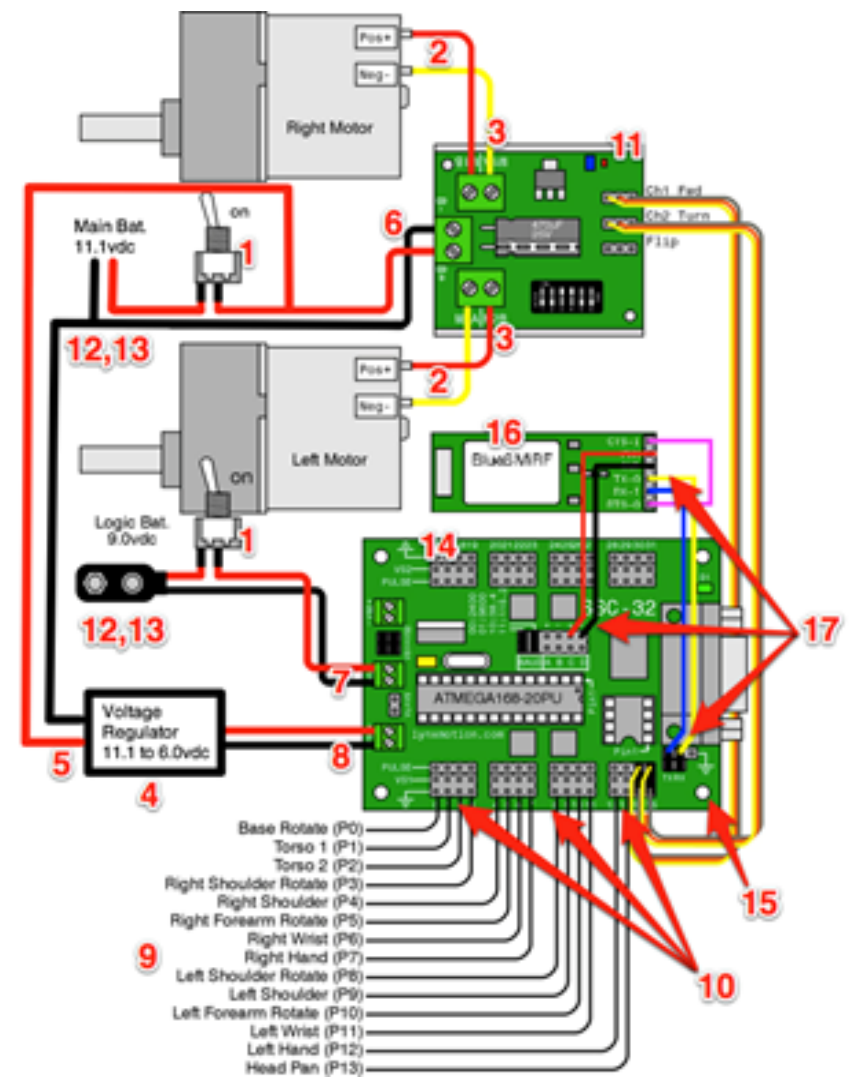

Figure 8: Diagram of redesigned electrical system for efficient assembly. of the repeatability tests for finding object location using Cartesian coordinates where base of robot is $[0,0]$ :

Trial 1: Detected at: $\mathrm{X}=157.00$ and $\mathrm{Y}=135.00$

Trial 2: Detected at: $\mathrm{X}=158.00$ and $\mathrm{Y}=135.00$

Trial 3: Detected at: $\mathrm{X}=157.00$ and $\mathrm{Y}=136.00$

Repeatability determined from the above tests is $99.63 \%$ which is considered very well for the intended applications.

\section{Other configurations of the developed modular robot}

Other configurations of the presented Modular Robot are displayed in Figures 12 and 13. Both, the two-arm and single arm robots are mounted on a screw-driven, rail mounted platform (linear slider mechanism) to add a seventh degree of freedom to the modular robot system. The two-arm robot is suitable for repair and assembly tasks inside the hot cell while the single arm robot is configured for precision materials handling tasks such as those used for disassembling annular targets for removal of irradiated nuclear
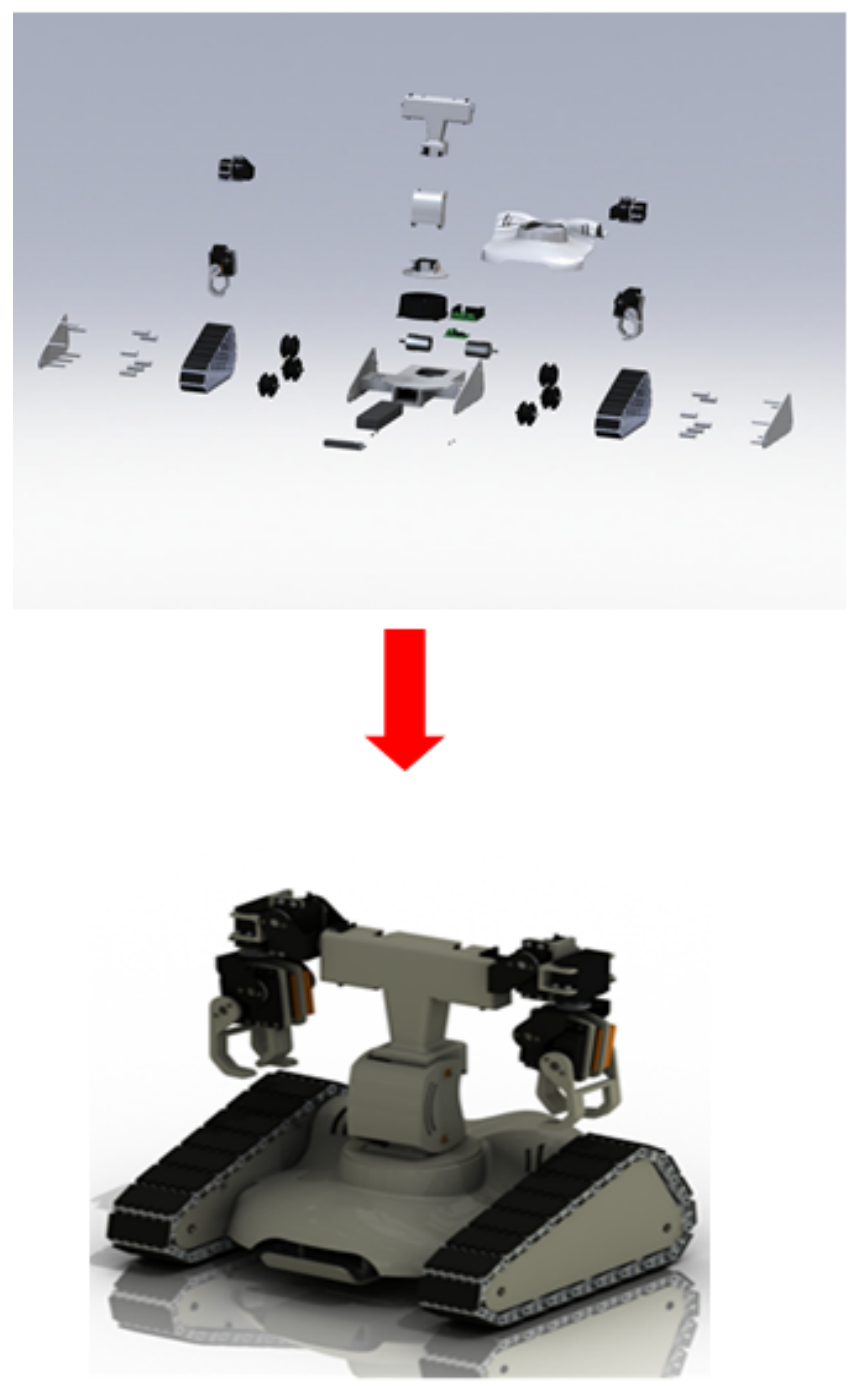

Figure 9: Exploded view and final product of the redesigned robot for efficient assembly. 
Citation: El-Gizawy AS, Kinsara A, Mousa G, Gunn A (2016) Development of Modular Robotic Design Concepts for Hot Cell Applications. Adv Robot Autom 5: 154. doi: 10.4172/2168-9695.1000154

Page 5 of 6

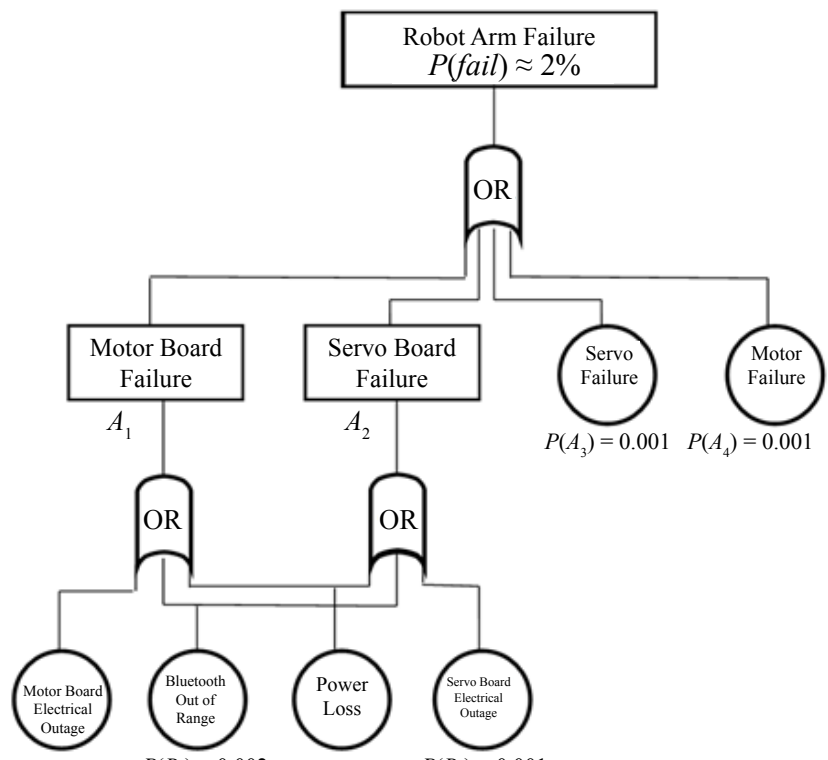

$P\left(B_{1}\right)=0.001 \quad P\left(B_{1}\right)=0.002 \quad P\left(B_{1}\right)=0.006 \quad P\left(B_{1}\right)=0.001$

Figure 10: Fault tree for the control system.
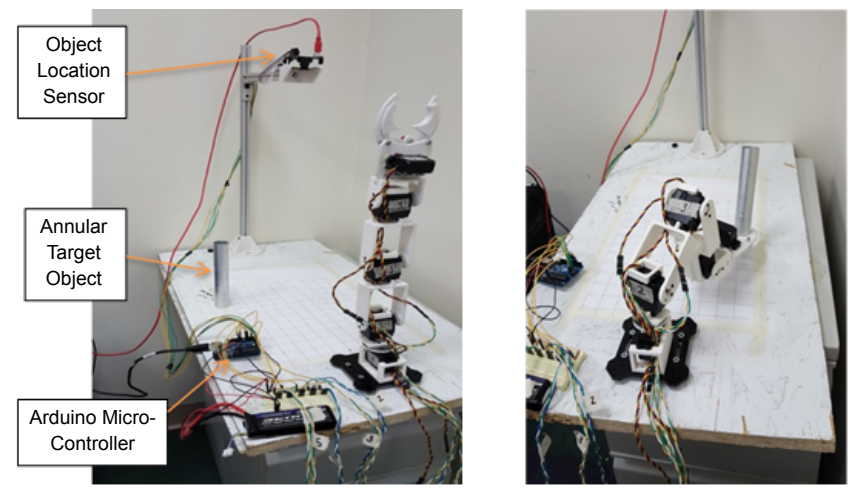

Figure 11: Setup for evaluating target reorientation and placing

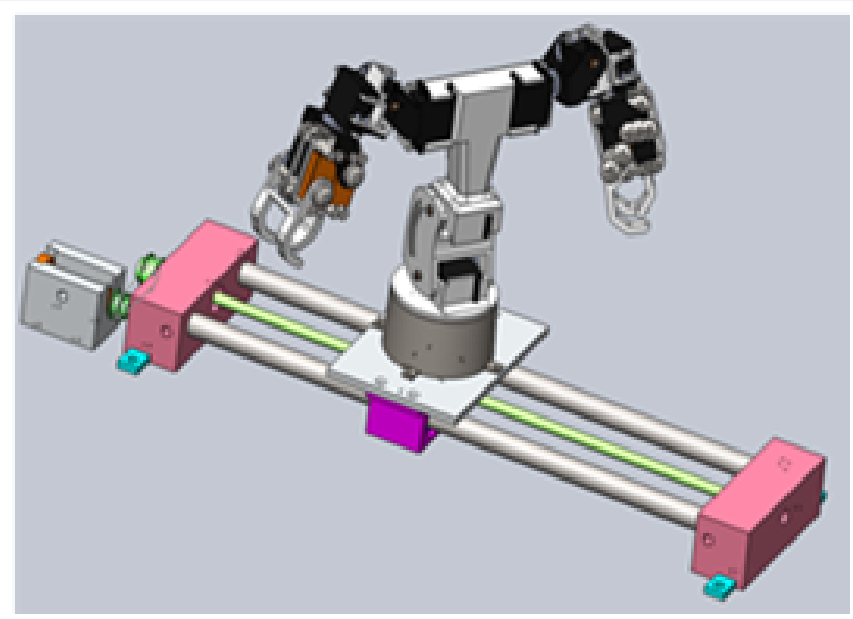

Figure 12: Two-arm modular robot on slider mechanism.

foil during the production of Mo-99 medical isotopes. It should be mentioned that all configurations of the modular robot are sized to have small footprints and to fit available hot cells. Any of the

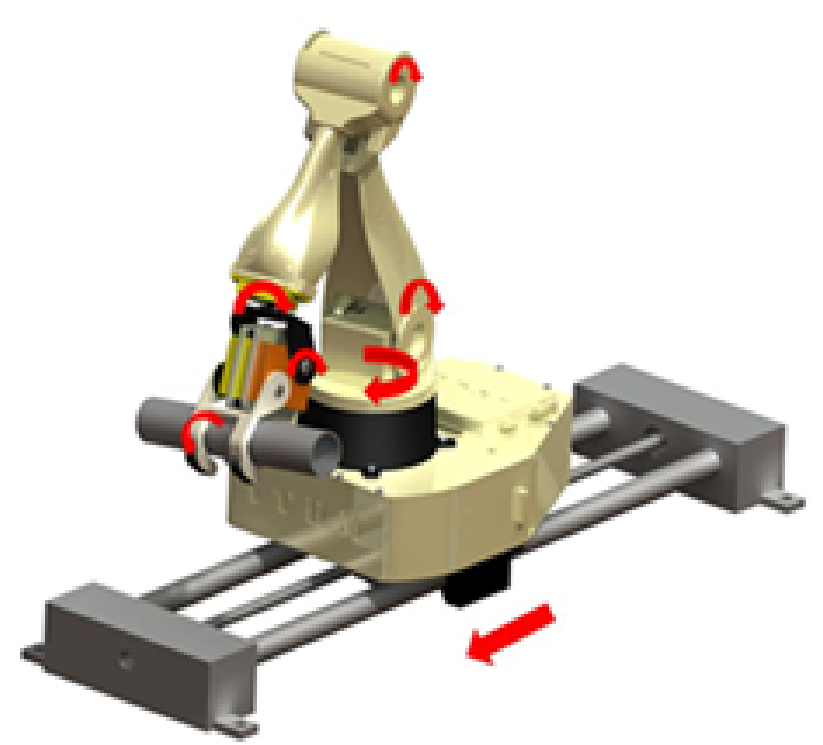

Figure 13: Single arm modular robot with seven degrees of freedom.

mentioned configurations would cost $\$ 5,000$ - $\$ 10,000$ compared with an average cost of $\$ 150,000-\$ 300,000$ for a master-slave mechanical manipulator or $\$ 75,000$ for commercially available 7 -degrees-offreedom robot that does not fit inside the hot cell and has limited capabilities for handling precision tasks.

\section{Conclusions}

- A modular robotic design for handling irradiated materials inside hot cells is introduced.

- The new robotic system is reconfigurable in order to enhance versatility of applications and precision of its tasks.

- The robotic control system is developed to be wireless using Bluetooth wireless capabilities.

- The reliability of the introduced robot control system is assessed using Failure Trees (FT) Methodologies.

- The technology developed in the present work helps in supporting modular robotics design for hazardous environments and allows for improving productivity and cost effectiveness for production of medical isotopes.

\section{Acknowledgements}

The authors wish to acknowledge the financial supports of King Abdul Aziz University, Saudi Arabia, STRATASYS, Inc. (USA), ITECH D\&M, LLC (USA) and Industrial Technology Development Center (University of Missouri), for the present research. Our appreciations are also extended to Engineering Students at University of Missouri and King Abdul Aziz University for their participation in the Robotic Projects and for providing the necessary efforts to make them successful.

\section{References}

1. Fogle RF (1992) The use of Teleoperators in Hostile Environment Applications Proc. Int. Conference. On Robotics and Automation (ICRA '92) Nice, France. pp: 61-66.

2. Ferner E, Hoyer A, El-Gizawy AS (2011) Remote Disassembly System for Annular Targets during Production of Mo-99. 2011 ANS Winter Meeting and Nuclear Technology Expo, Technical Conference Proceedings: The Status of Global Nuclear Deployment, Washington DC, American Nuclear Society (CDROM). p: 3 
Citation: El-Gizawy AS, Kinsara A, Mousa G, Gunn A (2016) Development of Modular Robotic Design Concepts for Hot Cell Applications. Adv Robot Autom 5: 154. doi: 10.4172/2168-9695.1000154

Page 6 of 6

3. Doroftei D, Matos A, de Cubber G (2014) Designing Search and Rescue Robots towards Realistic User Requirements, Applied Mechanics and Materials 658 612-617.

4. Doroftei D, Cubber GD, Chintamani K (2012) Towards collaborative human and robotic rescue workers, $5^{\text {th }}$ International Workshop on Human-Friendly Robotics (HFR2012).
5. Crane CD, Duffy J (2008) Kinematic Analysis of Robot Manipulators. Cambridge University Press

6. Gizawy ASE (2011) Process-induced Properties of FDM Products. Proceedings of The ICMET, International Conference on Mechanical Engineering and Technology Congress \& Exposition, ICMET 2011, Paris, France. p: 7. 